\title{
Bivalent inhibitors of c-Src tyrosine kinase that bind a regulatory domain
}

\author{
Taylor K. Johnson ${ }^{1}$, Matthew B. Soellner ${ }^{1,2}$ \\ ${ }^{1}$ Department of Medicinal Chemistry, University of Michigan, Ann Arbor, MI 48109. \\ ${ }^{2}$ Department of Chemistry, University of Michigan, Ann Arbor, MI 48109.
}

\begin{abstract}
We have developed a general methodology to produce bivalent kinase inhibitors for c-Src that interact with the SH2 and ATP binding pockets. Our approach led to a highly selective bivalent inhibitor of c-Src. We demonstrate impressive selectivity for c-Src over homologous kinases. Exploration of the unexpected high level of selectivity yielded insight into the inherent flexibility of homologous kinases. Finally, we demonstrate that our methodology is modular and both the ATP-competitive fragment and conjugation chemistry can be swapped.
\end{abstract}

\section{INTRODUCTION}

Protein kinases are key regulatory enzymes in human cell signaling, both in healthy and diseased tissue. Efforts to pharmacologically elucidate kinase signaling have been hampered by a lack of selective kinase inhibitors. ${ }^{1-3}$ The vast majority of reported kinase inhibitors bind to the conserved ATP-site. ${ }^{4}$ Owing to the conserved nature of the ATP pocket, nearly all ATP-competitive kinase inhibitors are promiscuous and bind to undesired off-targets. ${ }^{4-6}$ One strategy to improve the selectivity of kinase inhibitors is to interact with elements outside the conserved ATP pocket. ${ }^{7-9}$

We previously reported bisubstrate inhibitors of c-Src in which an ATP-competitive inhibitor was tethered to a substrate phosphorylation site peptide. ${ }^{10}$ Here, we explore the conversion of a promiscuous ATP-competitive kinase inhibitor into a bivalent inhibitor of c-Src that interacts with the SH2 domain of c-Src (in addition to the ATP-binding pocket). Our strategy involves conjugation of the two binding elements with "click chemistry" to enable a modular design. ${ }^{11}$ We demonstrate that both copper-catalyzed and catalyst-free strain-release click reactions ${ }^{12}$ can readily be employed to construct bivalent inhibitors. The modularity of our design is showcased by the synthesis of two distinct bivalent inhibitors starting from two different ATP-competitive inhibitor fragments.

Bivalent kinase inhibitors that target two distinct domains have been reported, ${ }^{8,9}$ however, there are no reports of such bivalent inhibitors purely constructed of small moleculepeptide hybrids. In addition, little is known about the selectivity changes transitioning from a

Correspondence: Matthew B. Soellner, Departments of Medicinal Chemistry and Chemistry, University of Michigan, $930 \mathrm{~N}$. University Ave., Ann Arbor, MI, 48109, USA. Tel: 734-615-2767, soellner@ med.umich.edu. 
promiscuous ATP-competitive inhibitor to a bivalent inhibitor also targeting a regulatory domain (here SH2 domain). ${ }^{13}$ Lawrence and co-workers reported fully peptidic bivalent inhibitors that link a substrate-phosphorylation site peptide to a $\mathrm{SH} 2$ domain interacting peptide. ${ }^{14,15}$ Maly and co-workers have reported linking ATP-competitive small molecules to $\mathrm{SH} 2$ domain binding peptides using a large, protein-based linker. ${ }^{16}$ In contrast, our design provides a significantly lower molecular weight bivalent inhibitor than either method previously described.

c-Src is known to exist in two distinct global conformations, open and closed (Figure 1). ${ }^{17,18}$ The open conformation is the conformation that exists associated with the plasma membrane and is known to correlate with disease progression. ${ }^{19}$ In contrast to the open conformation, the closed conformation is highly rigid. ${ }^{20}$ Crystal structures of the closed conformation reveal that the distance between the ATP-pocket and the phospho-Tyr binding pocket of the SH2 domain is $37 \AA$ (Figure 1 and Supplementary Figure S1) Due to the inherent rigidity of the inactive conformation, we hypothesized that we could selectively inhibit the open conformation using a bivalent inhibitor constructed with a linker shorter than $37 \AA$. We predicted that a bivalent inhibitor with a linker too short to interact with the closed, rigid conformation could still bind to the open, flexible conformation. To our knowledge, there has been no report of a c-Src inhibitor that can selectively inhibit the active conformation over the inactive conformation.

\section{RESULTS AND DISCUSSION}

Our design strategy involves ATP-competitive inhibitors with a pendant alkyne and a SH2 domain binding phospho-peptide containing a PEG linker and pendant azide (Scheme 1). ${ }^{21-23}$ We hypothesized that a linker shorter than $37 \AA$ A could provide an inhibitor that selectively inhibits the active conformation of c-Src. Thus, we elected to use a 33-atom PEG linker with a calculated maximal length of $25 \AA$ (Supplementary Figure S2). For an ATPcompetitive inhibitor, we selected an aminopyrazole fragment that is a promiscuous kinase inhibitor. ${ }^{24}$ We previously profiled an aminopyrazole fragment and found that it potently binds 117 of 200 kinases in that panel. ${ }^{25}$ To enable conjugation to a peptide, we synthesized $\mathbf{1}$, an aminopyrazole fragment with a pendant alkyne. We found $\mathbf{1}$ to be a competent inhibitor of 3-domain c-Src $\left(\mathrm{IC}_{50}=2.9 \mu \mathrm{M}\right)$. For the $\mathrm{SH} 2$ domain interacting peptide, we selected a previously reported pentapeptide, $\mathrm{H}_{2} \mathrm{~N}$-Q-pY-E-E-I-CONH $2 .{ }^{26}$ Solid phase peptide synthesis was employed to synthesize 2 , the $\mathrm{SH} 2$ interacting peptide with an $\mathrm{N}$-terminal azido linker.

${ }^{27}$ Copper-mediated click chemistry was then used to construct bivalent inhibitor 3 .

We evaluated bivalent inhibitor 3 in a continuous activity assay ${ }^{28}$ with 3-domain c-Src ${ }^{29}$ and found 3 was a potent inhibitor (Table $1, \mathrm{IC}_{50}=0.16 \mu \mathrm{M}$ ). Relative to ATP-competitive fragment $\mathbf{1}$, this represents a 18 -fold improvement in binding affinity. We next tested $\mathbf{3}$ against a kinase domain only construct of c-Src and found that bivalent inhibitor $\mathbf{3}$ has similar affinity to the ATP-competitive inhibitor alone $\left(\mathbf{3}, \mathrm{IC}_{50}=2.1 \mu \mathrm{M} ; \mathbf{1}, \mathrm{IC}_{50}=1.3 \mu \mathrm{M}\right)$. These results are consistent with bivalent inhibitor 3 requiring both the catalytic and SH2 domains to achieve optimal binding. Comparing kinase domain to 3-domain c-Src constructs, bivalent inhibitor 3 binds 13-fold tighter to the c-Src construct with an SH2 domain (Table 1). 
We hypothesized that using a linker shorter than the distance from the ATP-site to the SH2domain found in the crystal structure for inactive/closed conformation of c-Src (PDB: 2SRC) we could selectively target the more flexible active conformation of c-Src. To test this hypothesis, we utilized constructs of 3-domain c-Src that are active (pY416) ${ }^{30}$ and conformations known to be inactive and rigid (pY527 and SH2-engaged). ${ }^{17,31}$ Gratifyingly, we found that bivalent inhibitor 3 is a selective inhibitor of pY416 c-Src over the pY527 and SH2-engaged constructs (Table 1: pY416 IC $_{50}=0.24 \mu \mathrm{M}$, pY527 IC $_{50}=1.8 \mu \mathrm{M}$, SH2engaged $\mathrm{IC}_{50}=2.3 \mu \mathrm{M}$ ). In contrast, ATP-competitive inhibitor $\mathbf{1}$ has no preference for open vs closed c-Src constructs (see Supporting Information for details). To our knowledge, there are no reports for any kinase inhibitor with this level of selectivity for the active kinase conformation.

Next, we wanted to determine whether bivalent inhibitor $\mathbf{3}$ is selective for c-Src over homologous kinases. Thus, we tested both ATP-competitive inhibitor $\mathbf{1}$ and bivalent inhibitor $\mathbf{3}$ for inhibition against a panel of 8 homologous kinases, ${ }^{32}$ including 7 members of the Src family (Table 2). Importantly, each of these kinases includes a SH2 domain. ${ }^{33,34}$ The average $\mathrm{IC}_{50}$ for bivalent inhibitor $\mathbf{3}$ was $3.5 \mu \mathrm{M}$. From these data, we observe that $\mathbf{3}$ is highly selective (average of 22-fold selective) for c-Src across this panel of homologous kinases (Table 2). In addition, we observed only a modest increase in potency for bivalent inhibitor 3 compared to ATP-competitive inhibitor $\mathbf{1}$.

The level of selectivity we observed across homologous kinases is very impressive, however, it was unexpected given that the ATP-competitive inhibitor inhibits each kinase similarly and the $\mathrm{SH} 2$ binding element is known to interact with many Src family kinases. ${ }^{26,35} \mathrm{We}$ wanted to study the surprising selectivity using c-Src and Hck kinases. The ATP-competitive fragment binds with similar potency to both c-Src and Hck (c-Src IC $\mathrm{IC}_{50}=2.9 \pm 0.6 \mu \mathrm{M}$; Hck $\left.\mathrm{IC}_{50}=8.9 \pm 0.5 \mu \mathrm{M}\right)$ and cannot explain the selectivity observed for bivalent inhibitor $\mathbf{3}$. Next, to probe the affinity of the SH2 interacting peptide with both c-Src and Hck, we measured the affinity of a related $\mathrm{SH} 2$ peptide containing a N-terminal fluorophore and the same core residues as our bivalent inhibitor (FITC-E-P-Q-pY-E-E-I-P-I-Y-L-NH ${ }_{2}$, bold corresponds to the core $\mathrm{SH} 2$ binding residues found in bivalent inhibitor $\mathbf{3}$ ). We found the $\mathrm{SH} 2$ peptide binds to both c-Src and Hck with equal affinity (c-Src $\mathrm{EC}_{50}=0.72 \pm 0.1 \mu \mathrm{M}$, $\mathrm{Hck} \mathrm{EC}_{50}=1.0 \pm 0.3 \mu \mathrm{M}$ ). From these data, we conclude that the selectivity is not arising from either the ATP-competitive fragment or the SH2-binding element.

We hypothesized that the inter-domain flexibility for homologous kinases might be different - and thus responsible for the selectivity observed. To explore this hypothesis, we measured the binding of our bivalent inhibitor 3 to 3-domain Hck constructs with varied open/closed (flexible/rigid) conformations (in order of most open and flexible to most closed and rigid: wild-type, SH2-engaged, and SH3-engaged). ${ }^{36,37} \mathrm{We}$ found that bivalent inhibitor 3 binds tighter to SH3-engaged compared to wild-type 3-domain $\mathrm{Hck}\left(\mathrm{IC}_{50}=0.6\right.$ and $2.8 \mu \mathrm{M}$, respectively). These data suggest that activated Hck is less flexible than c-Src. Furthermore, engagement of the $\mathrm{SH} 3$ domain of Hck likely brings the $\mathrm{SH} 2$ and catalytic domains closer in proximity. Interestingly, Fyn1 is the only Src family kinase (SFK) other than c-Src for which 3 binds potently (Fyn $1 \mathrm{IC}_{50}=0.27 \mu \mathrm{M}$ ). A recent study of SFKs indicated that Fyn1 was significantly more flexible than other SFKs. ${ }^{38}$ Together, our findings reveal that homologous 
kinases have varied conformational flexibility, and that this flexibility can be selectively targeted using bivalent kinase inhibitors.

We have previously shown that bisubstrate kinase inhibitors are less susceptible to mutations within a single binding pocket. ${ }^{10}$ We wanted to determine whether bivalent inhibitor $\mathbf{3}$ could inhibit c-Src with a clinically relevant gatekeeper mutation (T338M) ${ }^{39}$ The T338M mutation renders c-Src resistant to nearly all ATP-competitive inhibitors, including all FDAapproved inhibitors of c-Src. ${ }^{40,41} \mathrm{We}$ found that bivalent inhibitor $\mathbf{3}$ is also potent inhibitor of 3-domain T338M c-Src $\left(\mathrm{IC}_{50}=0.19 \mu \mathrm{M}\right)$. These data suggest that bivalent inhibition of kinases is indeed an effective strategy to inhibit drug-resistant kinase mutants.

Our conjugation strategy, utilizing azide-alkyne click chemistry, was designed to be modular in nature. To showcase the modularity, we synthesized an analog of dasatinib (an FDAapproved dual c-Src/Abl inhibitor) with a pendant alkyne (see Supporting Information for details). Conjugation to the azido SH2 peptide 2 to dasatinib alkyne (S11) yielded bivalent inhibitor 4 (Figure 2). This inhibitor was too potent to evaluate in our enzymatic activity assays (due to titration of the lowest enzyme concentrations accessible to our activity assay). Thus, we utilized a commercial binding assay that is performed in reticukicyte lysate containing $\sim 5 \mathrm{mM}$ ATP (Luceome Biotechnologies, Tucson, AZ) ) $^{42,43}$ to measure the affinity of 4 with full-length c-Src. In this assay, compound $\mathbf{4}$ has an $\mathrm{IC}_{50}=1 \mathrm{nM}$ for full length Src, while the ATP-competitive fragment (dasatinib) has an $\mathrm{IC}_{50}$ of $18 \mathrm{nM}$. This represents an 18 -fold improvement in binding affinity upon conversion of the ATP-competitive fragment to bivalent inhibitor 4 . Notably, an 18 -fold improvement is identical to the binding affinity increase found with the aminopyrazole-based system. These data demonstrate that the ATPcompetitive inhibitor can be swapped for a different ligand in a straightforward manner. Thus, one could modulate selectivity (or other properties) by selecting from a multitude of known ATP-competitive kinase inhibitors.

Finally, we wanted to explore whether we could replace the copper-catalyzed click conjugation chemistry with a strain-release click chemistry. To enable catalyst-free conjugations, we synthesized dasatinib with a pendant cyclooctyne (Scheme S4). Incubation of azido peptide $\mathbf{2}$ with dasatinib cyclooctyne provided bivalent inhibitor 5 (Figure 2). In our enzymatic activity assay, this bivalent inhibitor titrates enzyme $\left(\mathrm{K}_{\mathrm{i}}<10 \mathrm{nM}\right)$, having similar activity to the copper catalyzed version (4). One advantage of catalyst-free cycloaddditions is the ability to perform on-enzyme conjugation in situations where copper might be toxic. ${ }^{12,44}$ This could enable rapid in situ generation of bivalent kinase inhibitors from starting fragments.

\section{CONCLUSION}

We have developed a platform to generate bivalent inhibitors that interact both with the ATPbinding site and a regulatory domain, here a $\mathrm{SH} 2$ domain. While the ATP pocket is conserved across the kinome, ${ }^{4}$ interaction with a $\mathrm{SH} 2$ domain can provide instant selectivity because the vast majority of kinases do not possess a SH2 domain. ${ }^{45}$ Furthermore, we found that our ATP-to-SH2 bivalent kinase inhibitors possess high selectivity across homologous kinase. We found that selectivity can be obtained even for kinases which share optimal SH2- 
peptide binding sequences. Using model kinases with varied flexibility, we demonstrated that flexibility of the kinase (in particular inter-domain flexibility) is responsible for the high level of selectivity obtained.

To demonstrate the modularity of our bivalent inhibitor design, we swapped the ATPcompetitive fragment to a dasatinib analog and obtained a bivalent inhibitor with single digit nanomolar potency. The conjugation chemistry can also be changed, here we used both copper-catalyzed and strain-promoted click reactions to synthesize bivalent inhibitors.

While outside the scope of this manuscript, we have previously demonstrated that peptidebased kinase inhibitors can be used in cellular assays after appending a cell-penetrating peptide. ${ }^{10}$ In addition, one could envision using small molecule SH2 ligands to construct fully non-peptide bivalent inhibitors that might have inherent cell permeability. These studies are ongoing in our laboratory.

\section{METHODS}

Materials and experimental methods are described in the Supporting Information.

\section{Supplementary Material}

Refer to Web version on PubMed Central for supplementary material.

\section{ACKNOWLEDGEMENTS}

We thank J. Kuriyan (UC Berkeley) for providing wild-type c-Src, Hck, and c-Abl expression plasmids. The University of Michigan College of Pharmacy financially supported this research. T.K.J. was supported, in part, by a National Institutes of Health Cellular Biotechnology Training Grant (GM008353).

\section{REFERENCES}

(1). Knight ZA, and Shokat KM (2005) Features of selective kinase inhibitors. Chem. Biol 12, 621637. [PubMed: 15975507]

(2). Zhang J, Yang PL, and Gray NS (2009) Targeting cancer with small molecule kinase inhibitors. Nat. Rev. Cancer 9, 28-39. [PubMed: 19104514]

(3). Brandvold KR, Steffey ME, Fox CC, and Soellner MB (2012) Development of a Highly Selective c-Src Kinase Inhibitor. ACS Chem. Biol 7, 1393-1398. [PubMed: 22594480]

(4). Manning G, Whyte DB, Martinez R, Hunter T, and Sudarsanam S (2002) The protein kinase complement of the human genome. Science. 298, 1912-1934. [PubMed: 12471243]

(5). Anastassiadis T, Deacon SW, Devarajan K, Ma H, and Peterson JR (2011) Comprehensive assay of kinase catalytic activity reveals features of kinase inhibitor selectivity. Nat. Biotechnol 29, 10391045. [PubMed: 22037377]

(6). Fabian MA, Biggs WH, Treiber DK, Atteridge CE, Azimioara MD, Benedetti MG, Carter TA, Ciceri P, Edeen PT, Floyd M, et al. (2005) A small molecule-kinase interaction map for clinical kinase inhibitors. Nat. Biotechnol 23, 329-336. [PubMed: 15711537]

(7). Breen ME, Steffey ME, Lachacz EJ, Kwarcinski FE, Fox CC, and Soellner MB (2014) Substrate Activity Screening with Kinases: Discovery of Small-Molecule Substrate-Competitive c-Src Inhibitors. Angew. Chem. Int. Ed 53, 7010-7013.

(8). Cox KJ, Shomin CD, and Ghosh I (2011) Tinkering outside the kinase ATP box: allosteric (type IV) and bivalent (type V) inhibitors of protein kinases. Futur. Med. Chem 3, 29-43. 
(9). Lamba V, and Ghosh I (2012) New directions in targeting protein kinases: focusing upon true allosteric and bivalent inhibitors. Curr. Pharm. Des 18, 2936-2945. [PubMed: 22571662]

(10). Brandvold KR, Santos SM, Breen ME, Lachacz EJ, Steffey ME, and Soellner MB (2015) Exquisitely Specific Bisubstrate Inhibitors of c-Src Kinase. ACS Chem. Biol 10, 1387-1391. [PubMed: 25793938]

(11). Kolb HC, Finn MG, and Sharpless KB (2001) Click Chemistry: Diverse Chemical Function from a Few Good Reactions. Angew. Chem. Int. Ed 40, 2004-2021.

(12). Agard NJ, Prescher JA, and Bertozzi CR (2004) A Strain-Promoted [3 + 2] Azide-Alkyne Cycloaddition for Covalent Modification of Biomolecules in Living Systems. J. Am. Chem. Soc 126, 15046-15047. [PubMed: 15547999]

(13). Gower CM, Thomas JR, Harrington E, Murphy J, Chang MEK, Cornella-Taracido I, Jain RK, Schirle M, and Maly DJ (2016) Conversion of a Single Polypharmacological Agent into Selective Bivalent Inhibitors of Intracellular Kinase Activity. ACS Chem. Biol 11, 121-131. [PubMed: 26505072]

(14). Hah J-M, Sharma V, Li H, and Lawrence DS (2006) Acquisition of a "Group A"-selective Src kinase inhibitor via a global targeting strategy. J. Am. Chem. Soc 128, 5996-5997. [PubMed: 16669643]

(15). Profit A, Lee T, and Lawrence D (1999) Bivalent inhibitors of protein tyrosine kinases. J. Am. Chem. Soc 121, 280-283.

(16). Hill ZB, Perera BGK, and Maly DJ (2009) A chemical genetic method for generating bivalent inhibitors of protein kinases. J. Am. Chem. Soc 131, 6686-6688. [PubMed: 19391594]

(17). Wenqing X, Harrison S, and Eck M (1997) Three-dimensional structure of the tyrosine kinase cSrc. Nature 385, 595-602. [PubMed: 9024657]

(18). Cowan-Jacob SW, Fendrich G, Manley PW, Jahnke W, Fabbro D, Liebetanz J, and Meyer T (2005) The Crystal Structure of a c-Src Complex in an Active Conformation Suggests Possible Steps in c-Src Activation. Structure 13, 861-871. [PubMed: 15939018]

(19). Yeatman TJ (2004) A renaissance for SRC. Nat. Rev. Cancer 4, 470-480. [PubMed: 15170449]

(20). Bernadó P, Pérez Y, Svergun DI, and Pons M (2008) Structural Characterization of the Active and Inactive States of Src Kinase in Solution by Small-Angle X-ray Scattering. J. Mol. Biol 376, 492-505. [PubMed: 18164031]

(21). Jung FH, Morgentin RR, and Ple P (2007) Quinoline derivatives as platelet-derived growth factor inhibitors, their preparation, pharmaceutical compositions, and use in the treatment of cancer. PCT Int. Appl 1-154.

(22). Moussa IA, Banister SD, Beinat C, Giboureau N, Reynolds AJ, and Kassiou M (2010) Design, synthesis, and structure-affinity relationships of regioisomeric N-benzyl alkyl ether piperazine derivatives as $\sigma-1$ receptor ligands. J. Med. Chem 53, 6228-6239. [PubMed: 20662542]

(23). Chen B-C, Droghini R, Lajeunesse J, Dimarco JD, Galella M, and Chidamdaram R (2005) Process for Preparing 2-aminothiazole-5-aromatic carboxamides as Kinase Inhibitors. US.

(24). Statsuk AV, Maly DJ, Seeliger MA, Fabian MA, Biggs WH, Lockhart DJ, Zarrinkar PP, Kuriyan J, and Shokat KM (2008) Tuning a three-component reaction for trapping kinase substrate complexes. J. Am. Chem. Soc 130, 17568-17574. [PubMed: 19053485]

(25). Kwarcinski FE, Fox CC, Steffey ME, and Soellner MB (2012) Irreversible Inhibitors of c-Src Kinase That Target a Nonconserved Cysteine. ACS Chem. Biol 7, 1910-1917. [PubMed: 22928736]

(26). Zhou S, Shoelson S, Chaudhuri M, Gish G, Pawson T, Haser W, King F, Roberts T, Ratnofsky S, Lechleider R, et al. (1993) SH2 domains recognize specific phosphopeptide sequences. Cell 72, 767-778. [PubMed: 7680959]

(27). Wang H, Yang C, Wang L, Kong D, Zhang Y, and Yang Z (2011) Self-assembled nanospheres as a novel delivery system for taxol: a molecular hydrogel with nanosphere morphology. Chem. Commun 47, 4439-4441.

(28). Wang Q, Cahill SM, Blumenstein M, and Lawrence DS (2006) Self-reporting fluorescent substrates of protein tyrosine kinases. J. Am. Chem. Soc 128, 1808-1809. [PubMed: 16464077] 
(29). Seeliger MA, Young M, Henderson MN, Pellicena P, King DS, Falick AM, and Kuriyan J (2005) High yield bacterial expression of active c-Abl and c-Src tyrosine kinases. Protein Sci 14, 31353139. [PubMed: 16260764]

(30). Cooper JA, and Howell B (1993) The when and how of Src regulation. Cell 73, 1051-1054. [PubMed: 7685656]

(31). Ayrapetov MK, Wang Y-H, Lin X, Gu X, Parang K, and Sun G (2006) Conformational basis for SH2-Tyr(P)527 binding in Src inactivation. J. Biol. Chem 281, 23776-23784. [PubMed: 16790421]

(32). Rabuck JN, Hyung S-J, Ko KS, Fox CC, Soellner MB, and Ruotolo BT (2013) Activation stateselective kinase inhibitor assay based on ion mobility-mass spectrometry. Anal. Chem 85, 69957002. [PubMed: 23845095]

(33). Nagar B, Hantschel O, Young MA, Scheffzek K, Veach D, Bornmann W, Clarkson B, SupertiFurga G, and Kuriyan J (2003) Structural basis for the autoinhibition of c-Abl tyrosine kinase. Cell 112, 859-871. [PubMed: 12654251]

(34). Boggon TJ, and Eck MJ (2004) Structure and regulation of Src family kinases. Oncogene 23, 7918-7927. [PubMed: 15489910]

(35). Liu BA, Jablonowski K, Shah EE, Engelmann BW, Jones RB, and Nash PD (2010) SH2 domains recognize contextual peptide sequence information to determine selectivity. Mol. Cell. Proteomics 9, 2391-2404. [PubMed: 20627867]

(36). Krishnamurty R, Brigham JL, Leonard SE, Ranjitkar P, Larson ET, Dale EJ, Merritt EA, and Maly DJ (2013) Active site profiling reveals coupling between domains in SRC-family kinases. Nat. Chem. Biol 9, 43-50. [PubMed: 23143416]

(37). Porter M, Schindler T, Kuriyan J, and Miller WT (2000) Reciprocal Regulation of Hck Activity by Phosphorylation of Tyr527 and Tyr416. J. Biol. Chem 275, 2721-2726. [PubMed: 10644735]

(38). Register AC, Leonard SE, and Maly DJ (2014) SH2-catalytic domain linker heterogeneity influences allosteric coupling across the SFK family. Biochemistry 53, 6910-6923. [PubMed: 25302671]

(39). Azam M, Seeliger MA, Gray NS, Kuriyan J, and Daley GQ (2008) Activation of tyrosine kinases by mutation of the gatekeeper threonine. Nat. Struct. Mol. Biol 15, 1109-1118. [PubMed: 18794843]

(40). Apsel B, Blair JA, Gonzalez B, Nazif TM, Feldman ME, Aizenstein B, Hoffman R, Williams RL, Shokat KM, and Knight ZA (2008) Targeted polypharmacology: discovery of dual inhibitors of tyrosine and phosphoinositide kinases. Nat. Chem. Biol 4, 691-699. [PubMed: 18849971]

(41). Getlik M, Grütter C, Simard JR, Klüter S, Rabiller M, Rode HB, Robubi A, and Rauh D (2009) Hybrid Compound Design To Overcome the Gatekeeper T338M Mutation in cSrc. J. Med. Chem 52, 3915-3926. [PubMed: 19462975]

(42). Jester BW, Cox KJ, Gaj A, Shomin CD, Porter JR, and Ghosh I (2010) A Coiled-Coil Enabled Split-Luciferase Three-Hybrid System: Applied Toward Profiling Inhibitors of Protein Kinases. J. Am. Chem. Soc 132, 11727-11735. [PubMed: 20669947]

(43). Jester BW, Gaj A, Shomin CD, Cox KJ, and Ghosh I (2012) Testing the Promiscuity of Commercial Kinase Inhibitors Against the AGC Kinase Group Using a Split-luciferase Screen. J. Med. Chem 55, 1526-1537. [PubMed: 22257127]

(44). Jewett JC, and Bertozzi CR (2010) Cu-free click cycloaddition reactions in chemical biology. Chem. Soc. Rev 39, 1272-9. [PubMed: 20349533]

(45). Liu BA, Shah E, Jablonowski K, Stergachis A, Engelmann B, and Nash PD (2011) The SH2 Domain-Containing Proteins in 21 Species Establish the Provenance and Scope of Phosphotyrosine Signaling in Eukaryotes. Sci. Signal 4, ra83-ra83. [PubMed: 22155787] 


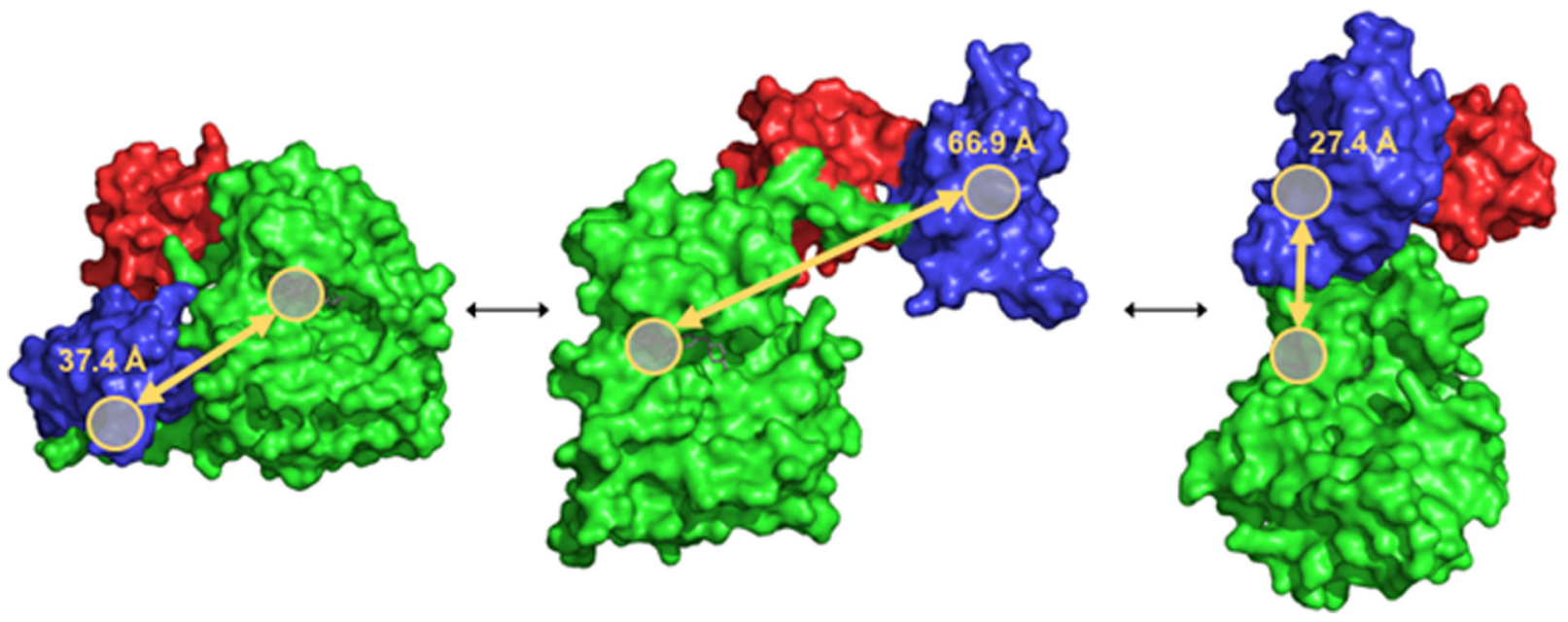

Figure 1. Conformational equibrium of c-Src.

c-Src exists in equilibrium between 'open' and 'closed' conformations. The closed, autoinhibited conformation (left, PDB: 1Y57), and open, active conformations (middle, PDB: 2SRC, and right, PDB: 1OPL). The kinase catalytic domains are colored green, SH2 domains colored blue, and SH3 domains colored red. For each conformation, distances between the ATP-binding pocket and the $\mathrm{SH} 2$ phosphotyrosine binding pockets are displayed and colored gold. 

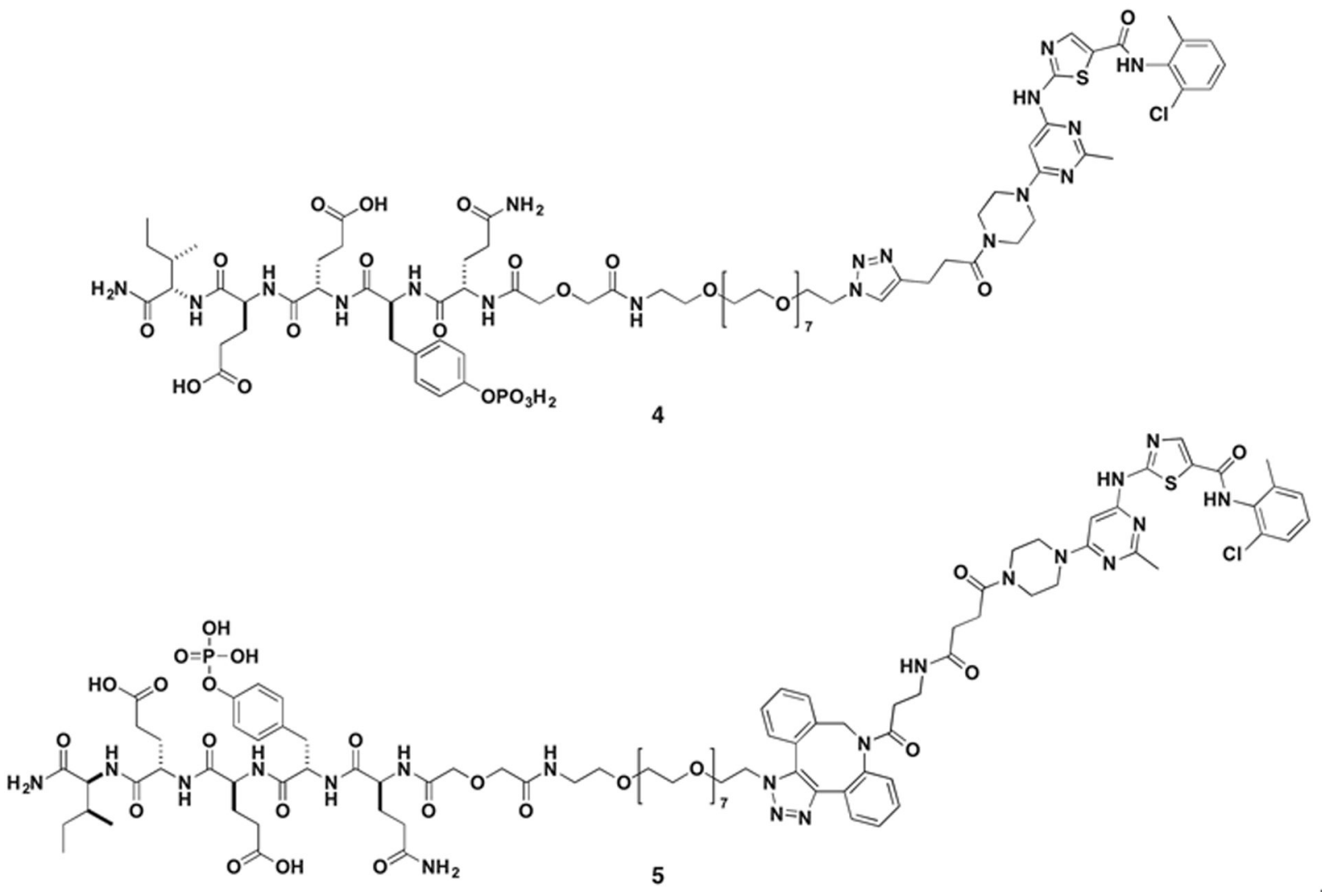

Figure 2. Dasatinib-based bivalent inhibitors.

Copper catalyzed dasatinib bivalent $\mathbf{4}$ and catalyst-free bivalent $\mathbf{5}$. 
<smiles>CC[C@H](C)[C@H](NC(=O)C(CCC(=O)O)NC(=O)[C@H](CCC(=O)O)NC(=O)C(Cc1ccc(OP(=O)(O)O)cc1)NC(=O)[C@H](CCC(N)=O)NC(=O)COCC(=O)NCCOC(C)(C)CC(C)(C)OCCN)C(N)=O</smiles>

2

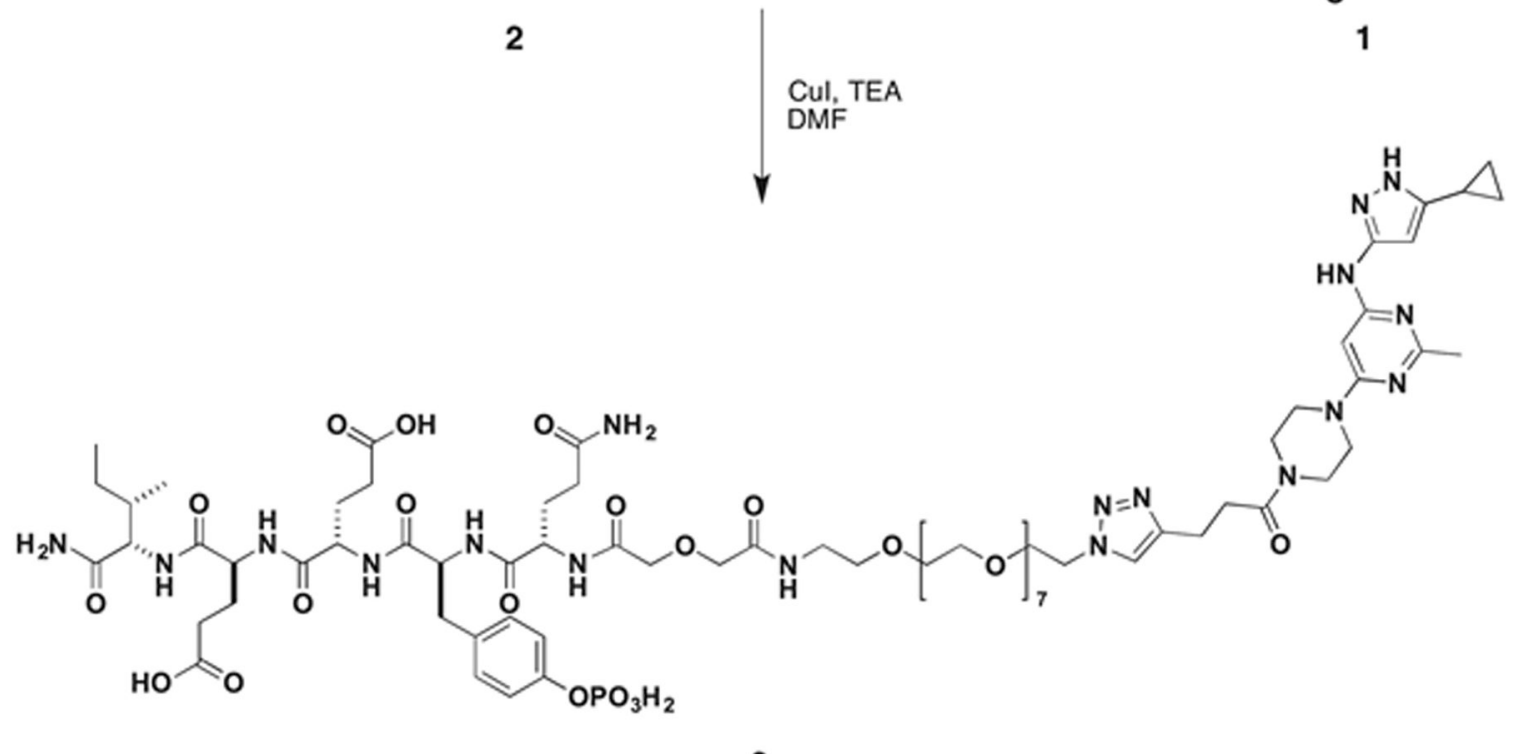

Scheme 1. Synthesis of bivalent inhibitor 3.

Copper catalyzed click cycloaddition of ATP-competitive alkyne $\mathbf{1}$ and azido-SH2-peptide $\mathbf{2}$ afford triazole-linked bivalent inhibitor $\mathbf{3}$. 
Table 1.

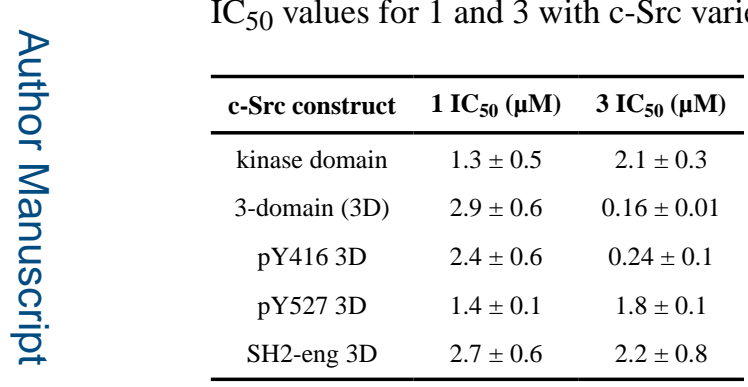


Table 2.

\begin{tabular}{|c|c|c|}
\hline kinase & $1 \mathrm{IC}_{50}(\mu \mathrm{M})$ & $3 \mathrm{IC}_{50}(\mu \mathrm{M})$ \\
\hline Hck & 8.9 & $2.8 \pm 0.7$ \\
\hline Lck & 9.3 & $5.3 \pm 0.6$ \\
\hline Blk & 21.8 & $5.3 \pm 0.7$ \\
\hline Frk & 9.6 & $5.6 \pm 0.4$ \\
\hline Fyn1 & 2.8 & $0.27 \pm 0.02$ \\
\hline Fgr & 4.6 & $3.1 \pm 0.9$ \\
\hline Lyn & 10.8 & $2.5 \pm 0.2$ \\
\hline $\mathrm{Abl}$ & 15.0 & $4.0 \pm 0.4$ \\
\hline
\end{tabular}

로을

롤

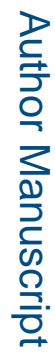

Bioconjug Chem. Author manuscript; available in PMC 2020 May 20. 